\begin{abstract}
Iranica
Abstracta Iranica Revue bibliographique pour le domaine irano-aryen

Volume 42-43 | 2021

Comptes rendus des publications de 2019-2020
\end{abstract}

\title{
Moritz Huber. Lives of Sogdians in Medieval China
}

\section{Alessia Zubani}

\section{OpenEdition}

Journals

Édition électronique

URL : https://journals.openedition.org/abstractairanica/53626

DOI : 10.4000/abstractairanica.53626

ISSN : 1961-960X

Éditeur :

CNRS (UMR 7528 Mondes iraniens et indiens), Éditions de l'IFRI

\section{Référence électronique}

Alessia Zubani, « Moritz Huber. Lives of Sogdians in Medieval China », Abstracta Iranica [En ligne], Volume 42-43 | 2021, document 7, mis en ligne le 30 décembre 2021, consulté le 18 décembre 2022. URL : http://journals.openedition.org/abstractairanica/53626 ; DOI : https://doi.org/10.4000/ abstractairanica.53626

Ce document a été généré automatiquement le 18 décembre 2022.

Tous droits réservés 


\title{
Moritz Huber. Lives of Sogdians in Medieval China
}

\author{
Alessia Zubani
}

\section{RÉFÉRENCE}

Moritz Huber. Lives of Sogdians in Medieval China. Wiesbaden: Harrassowitz Verlag, 2020, p. xvi + 350 (1er volume), p. 475 (2e volume online).

1 Version révisée d'une thèse de doctorat soutenue en 2017 à l'université Louis-etMaximilien de Munich, ce livre s'appuie sur un vaste corpus de sources littéraires et archéologiques pour contextualiser la présence sogdienne dans le monde chinois médiéval.

2 L'ouvrage est organisé en trois sections principales. Après une introduction (p. 1-10) portant sur l'histoire des études et la présentation de l'approche méthodologique de l'A., l'étude présente des recueils de textes chinois sur la Sogdiane (p. 11-103) et les Sogdiens en Chine (p. 105-217). Cette dernière section étudie en détail les tombes et épitaphes des Sogdiens en Chine ainsi que recueils littéraires de toutes sortes. Le chapitre 3 synthétise les sources primaires considérées dans les deux premières sections, en regroupant les informations selon des rubriques thématiques (par exemple, « monde militaire », « commerce », « traducteurs et émissaires »).

3 Un deuxième volume de 479 pages téléchargeable en format PDF depuis le site de l'éditeur (https://www.harrassowitz-verlag.de/title_6520.ahtml), complète la publication. Celui-ci rassemble les annexes, incluant tables, images (presque absentes du premier volume), rapports de fouilles, études sur les épitaphes des Sogdiens en Chine aussi bien que deux glossaires (l'un dédié à la toponomastique, l'autre aux termes techniques).

4 Malgré la présence de nombreuses erreurs typographiques, l'ouvrage constitue une référence importante pour l'histoire des Sogdiens dans la Chine médiévale, car il 
propose aux lecteurs un vaste corpus de sources primaires en chinois, souvent méconnues, accompagnées d'une traduction en anglais.

\section{AUTEURS}

\section{ALESSIA ZUBANI}

Labex HaStec, EPHE-PSL 